\title{
BENTUK-BENTUK GAYA BAHASA SINDIRAN PADA FILM COMIC 8 KASINO KING PART 2 KARYA ANGGY UMBARA (ANALISIS STRUKTURAL)
}

\author{
Harbeng Masni ${ }^{1}$, Pitri Yani ${ }^{2}$ \\ Program Studi Pendidikan Bahasa dan Sastra Indonesia, \\ Fakultas Keguruan dan Ilmu Pendidikan, Universitas Batanghari, \\ Jambi \\ harbeng.masni@yahoo.com \\ pitriyani0523@gmail.com
}

\begin{abstract}
The purpose of this study is to describe the forms of satirical language style in the film Comic 8 Casino King Part 2 by Anggy Umbara, which consists of three forms, namely irony, cynicism, and sarcasm. This research is a descriptive qualitative research with a structural approach. The primary data in this study are dialogues relating to satirical language style (irony, cynicism, sarcasm) contained in Comic 8 Movie Casino King Part 2 by Anggy Umbara. Secondary data in this study is a transcript of conversations from Comic 8 Casino King Part 2 by Anggy Umbara. Data were analyzed using the concepts of Tarigan, Keraf, and Purwandi. Based on the results of the analysis research it can be concluded that there are (1) the form of irony satire language style which is a subtle allusion, found in some data including the items, hair smells only, and longish Eh contained in seventeen quotes. (2) Cynicism satirical form of style which is a satire containing ridicule of sincerity and sincerity is found in some data including cowards, sissy, and killer forces contained in five quotations. (3) The form of sarcasm satire language style which is the most crude allusions found in some data including crazy, stupid, and use a little brain contained in eight quotations.
\end{abstract}

Keywords: Form, Satire, Film

\footnotetext{
${ }^{1}$ Dosen Program Studi Pendidikan Bahasa dan Sastra Indonesia, Fakultas Keguruan dan Ilmu Pendidikan, Universitas Batanghari, Jambi

${ }^{2}$ Mahasiswa Program Studi Pendidikan Bahasa dan Sastra Indonesia, Fakultas Keguruan dan Ilmu Pendidikan, Universitas Batanghari, Jambi
}

Bentuk-Bentuk Gaya Bahasa Sindiran pada Film Comic 8 Kasino King Part 2 Karya Anggy Umbara (Analisis Struktural) 


\section{PENDAHULUAN}

Karya sastra merupakan bentuk atau wujud gagasan dan pemikiran seseorang melalui pandangan terhadap lingkungan sosial yang berada di sekelilingnya dengan menggunakan bahasa yang indah. Sastra sebagai karya fiksi memiliki pemahaman yang lebih mendalam, bukan hanya sekedar cerita khayalan atau angan-angan dari pengarang saja melainkan wujud dari kreativitas pengarang dalam menggali dan mengolah gagasan yang ada dalam pikirannya (Tarigan, 1981: 143). Selain itu, karya sastra dapat digunakan untuk mengungkapkan berbagai hal yang ada pada kehidupan manusia. seperti keadaan sosial masyarakat dan permasalahan lain yang terjadi disekitar. Dalam karya sastra terdapat nilai-nilai kehidupan yang dapat dijadikan sebagai pembelajaran bagi manusia, oleh karena itu peneliti tertarik untuk mengkaji karya sastra khusus nya film.

Film adalah media sastra yang digunakan sebagai alat komunikasi yang lebih baik dibandingkan media sastra yang lainnya, tak hanya sebatas itu film memiliki kekuatan dan kemampuan menjangkau banyak segmen sosial sehingga film mampu mempengaruhi khalayaknya (Sobur, 2013: 127). Berdasarkan sumber tersebut maka film mampu menarik perhatian masyarakat karena mampu menunjukkan keeksitensiannya dan tetap bertahan di tengah masyarakat dan terus berkembang.

Film dapat didefinsikan sebagai karya senimatografi yang dapat berfungsi sebagai alat cultural education atau pendidikan budaya. Walaupun pada awalnya film dipergunakan sebagai karya yang diperjual-belikan serta sebagai media hiburan, namun pada perkembangannya film juga kerap digunakan sebagai media pembelajaran dalam dunia pendidikan. Gaya bahasa pada film tentu berbeda dengan gaya bahasa pada novel, puisi dan lainnya. Variasi gaya bahasa sindiran ini lah penulis dapat ditemukan pada ujaran atau percakapan di dalam film. Berdasarkan hasil observasi peneliti menemukan sebuah film di Indonesia berjudul Comic 8 Kasino King Part 2 karya Anggy Umbara yang sesuai untuk penelitian ini. Di dalam film yang berjenis action berbalut komedi ini terdapat variasi gaya bahasa yang dituturkan oleh tokohtokohnya.

Bahasa digunakan oleh manusia untuk melakukan interaksi atau berkomunikasi dengan sesama dalam kehidupan bermasyarakatan. Bahasa dan manusia merupakan dua hal yang tidak dapat dipisahkan, dalam arti keduanya saling berhubungan. Bahasa merupakan alat komunikasi yang paling penting bagi manusia karena dengan bahasa manusia dapat mengekspresikan apa yang ada dalam pikirannya. Agar komunikasi dapat berlangsung dengan baik, manusia harus menguasai keterampilan berbahasa karena hal tersebut mencerminkan pikiran, semakin terampil seseorang berbahasa maka semakin jelas pikirannya.

Sebuah bahasa memiliki gaya bahasa, yang mencerminkan cara seorang pengarang dalam menulis sebuah karya nya. Gaya bahasa diungkapkan dengan cara yang khas sehingga tujuan yang dimaksud dapat tercapai dengan maksimal. Gaya bahasa juga bisa membantu pembaca atau pendengar untuk membedakan karya masing-masing pengarang, karena setiap pengarang 
memiliki cara tersendiri dalam menyampaikan karyanya. Alasan penulis memilih gaya bahasa sindrian bahwa ada fenomena di dalam masyrakat bahwa etika bahasa kalau kita mau menegur itu lebih berterima dengan sindiran pada zaman dahulu. Tetapi sekarangn bergeser adanya pergeseran nilai dalam berkomunikasi terutama kalau ingin menegur seseorang. Dahulu orang yang ditegur lebih senang dengan disindir dan lebih memahami dengan disindir kalau sekarang tidak.

Berdasarkan latar belakang di atas banyak hal yang menarik di dalam penelitian ini, sebagai berikut.

1. Film banyak digemari masyarakat umum dari kalangan remaja, dewasa bahkan lanjut usia.

2. Film bermanfaat sebagai alat pendidikan budaya dan media hiburan yang dapat dinikmati masyarakat umum.

3. Film Comic 8 Kasino King Part 2 banyak menyajikan variasi gaya bahasa sindiran.

4. Gaya bahasa sindiran yang terdapat di dalam film menggunakan bahasa yang bermakna kiasan, sehingga yang menyimak tidak langsung mengetahui pesan apa yang di sampaikan oleh pengarang.

Berdasarkan uraian dan alasan di atas peneliti akhirnya memilih untuk meneliti tentang gaya bahasa sindiran. Penelitian ini penulis jadikan sebagai penyelesaian tugas akhir pada Program Studi Pendidikan Bahasa dan Sastra Indonesia, Jurusan Pendidikan Bahasa dan Seni, Fakultas Keguruan dan Ilmu Pendidikan. Universitas Batanghari. Penelitian ini penulis beri judul, "BentukBentuk Gaya Bahasa Sindirian Pada Film
Comic 8 Kasino King Part 2 Karya Anggy Umbar (Analisis Struktural).

Berdasarkan latar belakang di atas yang telah di uraikan, maka teridentifikasi masalah gaya bahasa sindiran terbagi menjadi: (1) Gaya Bahasa Ironi, (2) Gaya Bahasa Sinisme, (3) Gaya Bahasa Sarkasme.

Berdasarkan latar belakang dan identifikasi masalah yang telah penulis kemukahkan di atas, maka bentuk-bentuk gaya bahasa sindirian pada film Comic 8 Kasino King Part 2 karya Anggy Umbara, mengacu terhadap pendapat Tarigan (2013:61). Gaya bahasa sindiran mencakup tiga aspek yaitu: Ironi, Sinisme, Sarkasme.

Berdasarkan fokus penelitian di atas maka pertanyaan penelitian ini adalah sebagai berikut.

1. Bagaimanakah bentuk gaya bahasa ironi pada film Comic 8 Kasino King Part 2 karya Anggy Umbara?

2. Bagaimanakah bentuk gaya bahasa sinisme pada film Comic 8 Kasino King Part 2 karya Anggy Umbara?

3. Bagaimanakah bentuk gaya bahasa sarkasme pada film Comic 8 Kasino King Part 2 karya Anggy Umbara?

Tujuan penelitian merupakan sasaran yang hendak dicapai dalam sebuah penelitian. Sebelum penelitian dilakukan hendaknya tentukan terlebih dahulu tujuan yang akan dicapai. Sesuai dengan pertanyaan penelitian di atas, maka tujuan dalam penelitian ini adalah sebagai berikut.

1. Mendeskripsikan gaya bahasa ironi pada film Comic 8 Kasino King Part 2 karya Anggy Umbara.

2. Mendeskripsikan gaya bahasa sinisme pada film Comic 8 
Kasino King Part 2 karya Anggy Umbara.

3. Mendeskripsikan gaya bahasa sarkasme pada film Comic 8 Kasino King Part 2 Karya Anggy Umbara.

Berdasarkan tujuan penelitian, maka penelitian ini diharapkan dapat memberi manfaat kepada berbagai pihak. Terdapat dua macam manfaat yaitu, manfaat teoretis dan manfaat praktis yang dapat ditarik dalam penelitian ini.

Hasil dari penelitian ini diharapkan akan memberikan manfaat menambah ilmu pengetahuan dan wawasan tentang perkembangan ilmu sastra, terkhususnya dalam bidang gaya bahasa, terutama gaya bahasa sindiran yang terdapat dalam film.

Secara praktis, hasil dari penelitian ini diharapkan dapat memberikan manfaat untuk berbagai pihak, diantaranya:

1. bagi penulis, sebagai tambahan ilmu pengetahuan dan dapat menambah wawasan sehingga lebih memahami penggunaan gaya bahasa sindirian dalam penelitian film;

2. bagi guru bahasa Indonesia diharapkan dapat dijadikan sebagai acuan pembelajaran gaya bahasa secara mendasar, terutama pemanfaat gaya bahasa sindiran;

3. bagi peneliti berikutnya dapat memberikan wawasan atau pengalaman untuk penelitian selanjutnya serta bekal untuk memasuki dunia pendidikan dalam memperhatikan penggunaan gaya bahasa sindiran dalam sebuah tulisan.

\section{METODE PENELITIAN}

"Jenis penlitian berarti cara yang digunakan sesorang peneliti di dalam usaha memecahkan masalah yang diteliti (Siswantoro, 2010: 55)." Jenis penelitian dibutuhkan dalam kegiatan penelitian sebagai kunci jalannya sebuah penelitian. "Jenis penelitian berarti cara yang digunakan seseorang peneliti di dalam usaha memecahkan masalah yang diteliti (Siswantoro, 2014: 55).” Jenis penelitian ini merupakan suatu cara kegiatan ilmiah dalam memecahkan suatu masalah.

Penelitian kualitatif merupakan jenis penelitian yang lebih menekankan pada aspek pemahaman secara mendalam terhadap suatu masalah. "Penelitian kualitatif adalah penelitian yang digunakan untuk meneliti pada kondisi objek yang alamiah, di mana peneliti adalah sebagai instrumen kunci, teknik pengumpulan data dilakukan, penelitian kualitatif lebih menekankan makna berdasarkan paparan di atas, peneliti menyimpulkan bahwa penelitian ini menggunakan jenis penelitian deskriptif kualitatif, yaitu cara untuk memecahkan masalah dalam sebuah penelitian dengan menggambarkan atau melukiskan serta menginterpretasikan objek yang berupa gejala atau kejadian sosial pada kehidupan manusia sesuai data aslinya.

Berbagai jenis penelitian tidak akan pernah lepas dari data. Data yang baik bukan dilihat dari banyaknya jumlah data, melainkan kualitas data. "Analisis data merupakan suatu proses mengatur urutan data, mengorganisasikan ke dalam suatu pola, kategori, dan satuan uraian dasar (Patton dalam Muhammad 2011: 221).“ Data yang relevan menjadi syarat utama dalam penelitian untuk dijasikan sebagai bahasa penelitian. Adapun data dalam sebuah peneltian terbagi menjadi dua yaitu data primer dan data sekunder 
Merupakan data utama yang menjadi pokok utama dalam penelitian "sumber data terkait dengan subjek penelitian dari mana data diperoleh (Siswantoro, 2010: 72)." Sumber data primer berupa dialog yang menjadi sumber data yang wajib dalam penelitian ini, karena data primer merupakan sumber data yang berhubungan langsung dengan objek penelitian. Data primer dalam penelitian ini yaitu, dialog yang berkaitan tentang gaya bahasa sindiran (ironi, sinisme, sarkasme) yang terdapat dalam film Comic 8 Kasino King Part 2 karya Anggy Umbara.

Data sekunder merupakan data tambahan yang dapat mendukung dalam melakukan sebuah penelitian. "Data sekunder adalah data yang diperoleh secara tidak langsung atau lewat prantara, tetapi tetap bersandar kepada kategori atau parameter yang menjadi rujukan (Siswantoro, 2010: 71)." Data sekunder dalam penelitian ini merupakan transkip dari film Comic 8 Kasino King Part 2 karya Anggy Umbara.

Sumber data merupakan yang diperoleh dari sumber yang akan diteliti. "Sumber data terkait dengan subjek penelitian dari mana data diperoleh (Siswantoro, 2010:72)." Sumber data penelitian ini adalah terkait dengan dimana penulis mengambil dan penelitian tersebut. Sumber data dalam penelitian ini adalah film Comic 8 Kasino King Part 2 karya Anggy Umbara tahun 2016.

Pengumpulan data dalam sebuah penelitian merupakan hal yang sangat penting. Kualitas penelitian tergantung pada data penelitian. "Dalam pengumpulan data ketepatan pengambilan data tergantung pada ketajaman menyeleksi yang dipandu oleh penguasaan konsep atau pendapat
(Siswantoro, 2010:70)." Terkumpulnya data penelitian merupakan salah satu keberhasilan seorang penulis yang harus dilakukan dalam penelitian. Pengumpulan data dalam penelitian ini menggunakan teknik dokumentasi dan studi literatur yang memfokuskan analisis gaya bahasa sindiran dalam film Comic 8 Kasino King Part 2 Karya Anggy Umbara.

Teknik pengumpulan data dalam penelitian ini menggunakan teknik dokumentasi. "Dokumentasi merupakan proses pembuktian yang didasarkan atas jenis sumber apa pun, baik itu bersifat tulisan, lisan, gambaran, atau arkeologi (Gunawan, 2015:175)." Selanjutnya menurut Sugiyono (2018:329), "Dokumentasi merupakan catatan peristiwa yang sudah berlalu. Dokumentasi bisa berbentuk tulisan, gambar, atau karya-karya monumental dari seseorang." Dokumentasi digunakan untuk mengumpulkan data-data penelitian dalam film Comic 8 Kasino King Part 2 karya Anggy Umbara.

Analisis data merupakan upaya urgen dan praktis dalam sebuah penelitian. "Analisis data merupakan suatu proses mengatur urutan data, mengkordinasikan ke dalam suatu pola, kategori, dan satuan uraian dasar (Patton dalam Muhammad 2011: 221)." Analisis data penulis gunakan agar mendapatkan bentuk yang terkandung dalam sebuah data. Setelah seluruh data dari kumpulan Film Comic 8 Kasinio King Part 2 karya Anggy Umbara terkumpul berupa katakata dan kalimat yang berisikan gaya bahasa sindiran yang kemudian penulis pilah beberapa kutipan yang berhubungan dengan gaya bahasa sindiran serta menganalisis bentuk dalam film Comic 8 Kasinio King Part 2 karya Anggy Umbara dilakukan setelah semua data terkumpul. Dengan model alur yang 
dikemukakan oleh Miles dan Hubberman. Langkah-langkahnya adalah sebagai berikut:

1. Data yang telah diberikan tanda sesuai dengan pokok permasalahan kemudian ditabulasi ke dalam tabel tabulasi data.

2. Selanjutnya penulis menginterpretasikan data yang telah ditabulasi sesuai dengan bentuk gaya bahasa sindiran.

3. Penulis menganalisis data sesuai dengan bentuk dan makna gaya bahasa sindiran yang terdapat dalam Film Comic 8 Kasinio King Part 2 karya Anggy Umbara. Analisis bentuk dan makna gaya bahasa sindiran mengacu kepada pendapat Tarigan.

4. Penulis melakukan keabsahan data dengan mengkonsultasikan kepada pembimbing 1 dan pembimbing 2 kemudian hasil penelitian dikaitkan dengan metode penelitian serta data dicocokan dengan pendapat menurut Tarigan (2013).

5. Setelah dilakukan keabsahan data selanjutnya penulis mendeskripsikan hasil analisis bentuk Film Comic 8 Kasino King Part 2 karya Anggy Umbara.

6. Keabsahan Data

Dalam menguji keabsahan data penulis menggunakan teknik triangulasi. "Triangulasi adalah teknik pemeriksaan keabsahan data yang memanfaatkan sesuatu yang lain di luar data untuk keperluan atau pengecekan atau sebagai perbandingan terhadap data itu. Teknik triangulasi yang paling banyak digunakan ialah pemeriksaan melalui sumber lainnya (Moleong, 2012:330)." Dalam hal ini, melalui triangulasi akan di dapat keabsahan data yang valid.
7. Langkah terakhir penulis merumuskan kesimpulan

\section{HASIL DAN PEMBAHASAN}

Berdasarkan penelitian yang dilakukan, penulis menganalisis tentang bentuk gaya bahasa sindiran yang terdapat di dalam film Comic 8 Kasino King Part 2 Karya Anggy Umbara yaitu sebanyak 30 kutipan dari 3 aspek gaya bahasa sindiran yang ditemukan pada bentuk gaya bahasa sindiran aspek ironi tujuh kutipan, bentuk gaya bahasa sindiran aspek sinisme enam kutipan dan bentuk gaya bahasa sindiran aspek sarkasme delapan kutipan.

Pembahasan pada penelitian ini membahas tentang Bentuk Gaya Bahasa Sindiran pada Film Comic 8 Kasino King Part 2 Karya Anggy Umbara. Adapun yang didapat dalam hasil penelitian mengenai Bentuk Gaya Bahasa Sindiran pada Film Comic 8 Kasino King Part 2 Karya Anggy Umbara, dalam aspek ironi, sinisme, sarkasme. Tiga aspek ini akan dijelaskan satu-persatu dan berikut penjelasanya.

1) Aspek Gaya Bahasa Ironi dalam Film Comic 8 Kasino King Part 2 Karya Anggy Umbara

Ironi atau sinidiran adalah suatu acuan yang ingin mengatakan sesuatu dengan makna atau maksud berlainan dari apa yang terkandung dalam rangkaian kata-katanya. "Ironi adalah gaya yang menyatakan makna yang bertentangan dengan maksud berolokolok" (Tarigan, 2013:61). Gaya bahasa ironi suatu gaya bahasa yang akan mengatakan sesuatu dengan menggunakan makna dan maksud tersebut.

1. Cynthia: Nama saya Cynthia. Saya bekerja untuk Biro Pusat 
Nasional Asia dan Pasifik

Selatan. Saya ditugaskan ke sini intuk Investigasi semua aktivitas mencurigakan yang terkait dengan kasus perampokan Bank INI. Jadi berikan informasi yang saya minta. Sebelum kau masuk penjara. Paham tidak?. Ini foto yang diselamatkan dari crime scene. Ini foto-fotomu kan?.

Mongol: Coba liat ngana ganteng, hidung mancung nah dia pesek" coba ngana liat (menunjuk kearah foto yang ditunjukan Cynthia) (FC8KK:I.1)

Dalam Kutipan (FC8KK:I.1) terdapat gaya bahasa sindiran yang berbentuk ironi. Kutipan tersebut dapat dianalisis dari dialog film "Coba liat ngana ganteng, hidung mancung nah dia pesek, arti dari kutipan ini sebenarnya dia tidak ganteng dan hidungnya tidak mancung, Mongol mengatakan tidak sesuai dengan apa yang dibicarakan, sehingga dia menyatakan kalimat sindiran yang halus. Hal ini sesuai dengan pendapat Purwandari (2012: 206) Gaya bahasa sindiran paling halus yang menggunakan kata-kata yang artinya justru sebaliknya dengan maksud pembicara. Karena pada kutipan tersebut Mongol menyatakan kata-kata yang artinya justru sebaliknya.

2. Indro: Interpol.

Enceh (satpam): iya saya tau pak indro. Inter, internal gitu. kalo saya kan eksternal ngider. "Saya juga dulu hampir jadi polisi cuma waktu tes masuk saya tidur. Tapi diterima saya jadi polisi tidur." (FC8KK:I.2)

Dalam Kutipan (FC8KK:I.2) terdapat gaya bahasa sindiran yang berbentuk ironi. Kutipan tersebut dapat dianalisis dari dialog film "Saya juga dulu hampir jadi polisi cuma waktu tes masuk saya tidur. Tapi diterima saya jadi polisi tidur." Karena pada kalimat tersebut menjelaskan bahwa Satpam menyatakan kata-kata yang berolok-olok yang artinya bermain-main (dengan maksud menyindir, mengejek) dengan perkataan yang bersenda gurau Tapi diterima saya jadi polisi tidur. Hal ini sesuai dengan pendapat (Tarigan, 2013:61) "Ironi adalah gaya yang menyatakan makna yang bertentangan dengan maksud berolok-olok."

3. The king: Kamu nanya itu, aku rubah semuanya, Cuma yang satu itu aku tinggalin buat kamu, khusus buat kamu.

dr. Pandji: "Ni ada yang masang $A C$ atau gimana ni, agak dingin ya." (FC8KK:I.3)

Dalam Kutipan (FC8KK:I.3) terdapat gaya bahasa sindiran yang berbentuk ironi. Kutipan tersebut dapat dianalisis dari dialog film, "Ni ada yang masang $A C$ atau gimana ni, agak dingin ya." Arti dari kalimat ini sebenarnya kondisi suhu di ruangan saat itu sangat panas dan tidak ada $\mathrm{AC}$ di dalam ruangan tersebut sehingga dia menyatakan kalimat sindiran yang halus. Hal ini sesuai dengan pendapat Purwandari (2012: 206), "Gaya bahasa sindiran paling halus yang menggunakan katakata yang artinya justru sebaliknya dengan maksud pembicara." Karena pada kutipan tersebut Mongol menyatakan kata-kata yang artinya justru sebaliknya. 4. Willy: (adegan fighting).

Bentuk-Bentuk Gaya Bahasa Sindiran pada Film Comic 8 Kasino King Part 2 Karya Anggy Umbara (Analisis Struktural) 
Fico: Nggak sakit ni, lawan aja lawan, nggk sakit.

Babe: Nah kalau gitu fighting aja. aduh kok aku sakit ni. (FC8KK:I.4)

Dalam kutipan (FC8KK:I.4) terdapat gaya bahasa sindiran yang berbentuk ironi. Kutipan tersebut dapat dianalisis dari dialog film, "Nggak sakit ni, lawan aja, nggak sakit." Arti dari kalimat ini sebenarnya Fico merasa sangat kesakitan akibat adegan fighting tersebut tetapi dia mengucapkan kalimat yang sebaliknya. Hal ini sesuai dengan pendapat Purwandari (2012: 206), "Gaya bahasa sindiran paling halus yang menggunakan kata-kata yang artinya justru sebaliknya dengan maksud pembicara." Karena pada kalimat tersebut menjelaskan bahwa Fico menyatakan kata-kata yang artinya justru sebaliknya.

Dari hasil penelitian dapat penulis simpulkan bahwa film Comic 8 Kasino King Part 2 Karya Anggy Umbara tersebut dialognya ditulis dengan menggunakan bahasa sindirian berbentuk ironi, dan dialog ditulis dengan menggunakan bahasa yang bertentangan dengan maksud berolok-olok. Penulis menemukan bahwa gaya bahasa ironi dalam film Comic 8 Kasino King Part 2 digunakan untuk mendapatkan efek menarik pada film tersebut. Gaya bahasa ironi yang ditemukan dalam Comic 8 Kasino King Part 2 Karya Anggy Umbara yaitu berjumlah 17 kutipan. Analisis data secara lengkap dapat dilihat dalam table 3 halaman 116.

\section{Aspek Gaya Bahasa Sinisme dalam Film Comic 8 Kasino King Part 2 Karya Anggy Umbara}

Gaya bahasa sinisme merupakan gaya bahasa yang digunakan untuk menyatakan sindiran secara langsung. "Sinisme adalah jenis gaya bahasa yang berupa sindiran yang berbentuk kesangsian yang mengandung ejekan terhadap keikhlasan dan ketulusan hati" (Tarigan, 2013:91). Gaya bahasa ini lebih kasar dari bahasa ironi.

1. Kemal: Sudah Nest jangan dilawan Nest, ntar dikutuk jadi batu. Becanda aja Nest, becanda.

Arie: Opa, sabar ya opa. Orang tua dilawan, parah kau Ernest. (FC8KK:S.1)

Dalam kutipan (FC8KK:S.1) terdapat gaya bahasa sindiran yang berbentuk sinisme. Kutipan tersebut dapat dianalisis dari dialog film, "Sudah Nest jangan dilawan Nest, ntar dikutuk jadi batu. Becanda aja Nest, becanda." Karena pada kutipan tersebut menjelaskan Kemal hanya sekedar ejekan ,mengandung ungkapan yang sinis dan ejekan tentang ketulusan hati. Hal ini sesuai dengan pendapat (Tarigan, 2013:91) "Sinisme adalah jenis gaya bahasa yang berupa sindiran yang berbentuk kesangsian yang mengandung ejekan terhadap keikhlasan dan ketulusan hati."

2. Fico: wah... berarti bener mereka pasukan pembunuh. lo sih nggk percaya.

Bintang: Kan tadi lu yang nggk percaya. (FC8KK:S.2)

Dalam Kutipan (FC8KK:S.2) terdapat gaya bahasa sindiran yang berbentuk sinisme. Kutipan tersebut dapat dianalisis dari dialog film, "wah... berarti bener mereka pasukan pembunuh. lo sih nggk percaya." Karena pada kalimat tersebut menyatakan kesangsian terhadap kutipan tersebut. Hal 
ini sesuai dengan pendapat (Tarigan, 2013:91) "Sinisme adalah jenis gaya bahasa yang berupa sindiran yang berbentuk kesangsian yang mengandung ejekan terhadap keikhlasan dan ketulusan hati."

4. Isa : Eh banci diam lo.

Mongol: Eh dia bilang kita banci.

Dalam kutipan (FK8KK:S.4) terdapat gaya bahasa sindiran yang berbentuk sinisme. Kutipan tersebut dapat dianalisis dari dialog film, "Eh banci diam lo." Karena pada kalimat tersebut menyatakan bahwa Isa memanggil Monggol dengan sebutan banci. Dalam Kamus Besar Bahasa Indonesia arti kata banci ialah laki-laki yang bertingkah laku dan berpakaian perempuan, Kutipan (FK8KK:S.4) mengandung ungkapan yang sinis dan ejekan tentang ketulusan hati. Hal ini sesuai dengan pendapat (Tarigan, 2013:91), "Sinisme adalah jenis gaya bahasa yang berupa sindiran yang berbentuk kesangsian yang mengandung ejekan terhadap keikhlasan dan ketulusan hati."

5. Enceh (Satpam): Tante polwan saya takut.

Cynthia: Jangan jadi pengecut. kau mau aku bagaimana

Indro: Ulur waktu.

Dalam kutipan (FC8KK:S.5) terdapat gaya bahasa sindiran yang berbentuk sinisme. Kutipan tersebut dapat dianalisis dari dialog film, "Jangan jadi pengecut. kau mau aku bagaimana?." Karena pada kalimat tersebut menjelaskan bahwa Cynthia hanya menggertak agar tidak jadi pengecut yang artinya penakut, kutipan (FC8KK:S.5) mengandung ungkapan yang sinis dan ejekan tentang ketulusan hati. Hal ini sesuai dengan pendapat (Tarigan, 2013: 91) "Sinisme adalah jenis gaya bahasa yang berupa sindiran yang berbentuk kesangsian yang mengandung ejekan terhadap keikhlasan dan ketulusan hati."

Dari hasil penelitian dapat disimpulkan bahwa film Comic 8 Kasino King Part 2 Karya Anggy Umbara tersebut dialognya ditulis dengan menggunakan bahasa sindirian berbentuk sinisme, dan dialog ditulis dengan menggunakan bahasa yang berbentuk kesangsian. Penulis menemukan bahwa gaya bahasa ironi dalam film Comic 8 Kasino King Part 2 digunakan untuk mendapatkan efek menarik pada film tersebut. Gaya bahasa sinisme yang ditemukan dalam Comic 8 Kasino King Part 2 Karya Anggy Umbara yaitu berjumlah 5 kutipan. Analisis data secara lengkap dapat dilihat dalam table 4 halaman 131.

\section{3) Aspek Gaya Bahasa Sarkasme dalam Film Comic 8 Kasino King Part 2 Karya Anggy Umbara}

Sarkasme dapat saja bersifat ironis, dapat juga tidak, tetapi yang jelas adalah bahwa gaya ini selalu menyakitkan hati dan kurang enak didengar, "Gaya bahasa sindiran yang menggunakan kata-kata yang kasar. Biasanya gaya bahasa ini dipakai untuk menyatakan amarah" (Purwandari, 2012:206). Dengan demikian sarkasme merupakan sebuah karya yang diciptakan oleh penulis agar dapat dinikmati oleh penikmatnya.
1. Fico : Eh.. stop..stop. Eh ini kita berantemnya ada batas waktunya nggksih?
Babe : Suka-suka kau, bebas. 
Willy : Kayak mana kalau batasnya,

batas nyawa sampai
ketenggorokkan
(FC8KK:SA.1)

Dalam kutipan (FC8KK:SA.1) terdapat gaya bahasa sindiran yang berbentuk sarkasme. Kutipan tersebut dapat dianalisis dari dialog film, "Batas nyawa sampai ketenggorokkan lo" Karena pada kutipan tersebut menjelaskan bahwa Willy menyatakan amarah terhadap Fico. Hal ini sesuai dengan pendapat Purwandari (2012: 206), "Gaya bahasa sindiran yang menggunakan kata-kata yang kasar, biasanya gaya bahasa ini dipakai untuk menyatakan amarah."

2. Kemal: Eh... stop.. stop... istirahat... istirahat

Ernest: istirahat..istirahat.. mau mati lo.

Belum naik haji udah mau mati lo. (FC8KK:SA:2)

Dalam kutipan (FC8KK:SA:2) terdapat gaya bahasa sindiran yang berbentuk sarkasme. Kutipan tersebut dapat dianalisis dari dialog film, "Istirahat.. istirahat.. mau mati lo. Belum naik haji udah mau mati lo." Karena pada kutipan tersebut menjelaskan bahwa Ernest menyatakan kalimat tidak langsung dengan perumpamaan kata mati. Dalam Kamus Besar Bahasa Indonesia berarti sudah hilang nyawanya, tidak hidup lagi. Hal ini sesuai dengan pendapat (Purwandari, 2012:206) "Gaya bahasa sindiran yang menggunakan katakata yang kasar, biasanya gaya bahasa ini dipakai untuk menyatakan amarah."

3. Fico: Kata orang kalau nggak ada singkong, akar pun jadi.

Babe: Mak... udah gila kau ya. Emang akar kalau dibakar bisa enak (FC8KK:SA:3)

\section{Dalam kutipan (FC8KK:SA:3)} terdapat gaya bahasa sindiran yang berbentuk sarkasme. Kutipan tersebut dapat dianalisis dari dialog film, "Mak... udah gila kau ya. Emang akar kalau dibakar bisa enak." Karena pada kutipan tersebut menjelaskan bahwa Babe menyatakan kalimat tidak langsung dengan perumpamaan kata gila. Dalam Kamus Besar Bahasa Indonesia berarti gangguan jiwa, sakit ingatan (kurang beres ingatannya). Hal ini sesuai dengan pendapat Purwandari (2012:206), "Gaya bahasa sindiran yang menggunakan katakata yang kasar, biasanya gaya bahasa ini dipakai untuk menyatakan amarah."

4. Georgi: Dasar dungu bikin api unggun di tengah permainan saling bunuh.

Bintang: Nah kan jangan-jangan itu pasukan pembunuh yang tadi. (FC8KK:SA.4)

Dalam kutipan (FC8KK:SA.4) terdapat gaya bahasa sindiran yang berbentuk sarkasme. Kutipan tersebut dapat dianalisis dari dialog film, "Dasar dungu bikin api unggun di tengah permainan saling bunuh." Karena pada kutipan tersebut menjelaskan bahwa Georgy menyatakan kalimat tidak langsung dengan perumpamaan kata dungu. Kata dungu dalam Kamus Besar Bahasa Indonesia berarti sangat tumpul otaknya, tidak cerdas, bebal atau bodoh. Hal ini sesuai dengan pendapat Purwandari (2012:206), "Gaya bahasa sindiran yang menggunakan kata-kata yang kasar, biasanya gaya bahasa ini dipakai untuk menyatakan amarah."

Dari hasil penelitian dapat penulis simpulkan bahwa film Comic 8 Kasino King Part 2 Karya Anggy Umbara tersebut dialognya ditulis dengan menggunakan bahasa sindirian berbentuk 
sarkasme, dan dialog ditulis dengan menggunakan bahasa yang kasar. Penulis menemukan bahwa gaya bahasa ironi dalam film Comic 8 Kasino King Part 2 digunakan untuk mendapatkan efek menarik pada film tersebut. Gaya bahasa ironi yang ditemukan dalam Comic 8 Kasino King Part 2 Karya Anggy Umbara yaitu berjumlah 8 kutipan.

\section{SIMPULAN}

Berdasarkan hasil penelitian, maka dapat disimpulkan tentang bentuk gaya bahasa sindiran dalam film Comic 8 Kasino King Part 2 karya Anggy Umbara. Bentuk gaya bahasa sindiran tersebut mencakup 3 bentuk yaitu:

1. Bentuk gaya bahasa ironi yang mencakup gaya bahasa sindiran halus dengan menggunakan katakata yang artinya justru sebaliknya, gaya bahasa yang menyatakan makna yang bertentangan dengan maksud berolok-olok, dapat peneliti temukan 17 jumlah gaya bahasa ironi yang terdapat pada film Comic 8 Kasino King Part 2 karya Anggy Umbara.

2. Bentuk gaya bahasa sinisme yang mencakup gaya bahasa berbentuk kesangsian, menganduk ejekan terhadap keikhlasan dan ketulusan hati, dapat peneliti temukan 5 jumlah gaya bahasa sinisme yang terdapat pada film Comic 8 Kasino King Part 2 karya Anggy Umbara.

3. Bentuk gaya bahasa sarkasme yang mencakup gaya bahasa sindiran yang paling kasar, gaya bahasa yang dipakai untuk menyatakan amarah, sindiran yang pedas dan menyakitkan hati. Dapat peneliti temukan 8 jumlah gaya bahasa sarkasme yang terdapat pada film
Comic 8 Kasino King Part 2 karya Anggy Umbara.

Dengan demikian bentuk gaya bahasa sindiran dalam film Comic 8 Kasino King Part 2 Karya Anggy Umbara, yang paling dominan ditemukan yaitu bentuk ironi, sarkasme dan yang paling sedikit ditemukan yaitu bentuk sinisme.

\section{SARAN}

Berdasarkan kesimpulan yang diperoleh dalam penelitian ini, maka ada beberapa saran yang perlu penulis kemukakan, saran tersebut sebagai berikut.

1. Saat menonton sebuah film dibutuhkan sikap kritis untuk tidak hanya menerima cerita yang disuguhkan dengan apa adanya, penonton harus lebih aktif dalam menggali pesanpesan tersirat dalam sebuah cerita atau adegan melalui ucapan-ucapan ataupun dialog yang dilakukan oleh aktor yang ada dalam film Comic 8 Kasino King Part 2 tersebut sehingga penonton tidak hanya menjadi korban cerita tetapi dapat memahami pesan yang disampaikan melalui film tersebut.

2. Gaya bahasa sindiran sangat bermanfaat di hadirkan di dalam film agar yang menonton tidak merasa bosan dan nada pembelajaran di balik semua sindiran itu, maka dari itu penulis sangat tertarik meneliti gaya bahasa sindiran. Penulis menyampaikan bahwa dalam setiap gaya bahasa sindiran mempunyai sifat dan makna yang berbeda-beda, dengan demikian pembaca dapat menentukan mana yang baik dan mana yang tidak baik. 
DAFTAR PUSTAKA

Endraswara, Suwardi. (2011). Metode Pembelajaran Drama. Yogyakarta. CAPS.

Gunawan, Imam. (2015). Metode Penelitian Kualitatif Teori dan Praktik. Jakarta: Bumi Aksara.

Keraf, Gorys. 2009. Diksi dan Gaya Bahasa. Jakarta: PT Gramedia Pustaka Utama.

Moleong, Lexy. J. (2009). Metodelogi Penelitian Kualitatif. Bandung: PT Remaja Rosdakarya.

Purwandi, Retno dan Qoni'ah. (2012). Buku Pintar Bahasa Indoneisa. Yogyakarta: Familia.

Siswantoro. (2010). Metode Penelitian Sastra. Yogyakarta: Pustaka Pelajar.

Sugiyono. (2007). Metode Penelitian Pendidikan: Pendekatan Kuantitatif dan $R \& D$. Bandung: Alfabeta.

Tarigan, Henry Guntur. (2013). Pengajaran Gaya Bahasa. Bandung: Angkasa Bandung. 